\title{
Quantitative Analysis of Data Mining Application and Sports Industry Financing Mechanism based on Cloud Computing
}

\author{
Hao Wang ${ }^{1,2}$ and Jinhai Sun ${ }^{3, *}$ \\ ${ }^{1}$ School of Physical Education and Sports Science, Qufu Normal University, \\ 273100 Qufu City, China \\ ${ }^{2}$ School of Sport Social Science, Shandong Sport University, China \\ ${ }^{3}$ College of physical education, Shandong University, China \\ Corresponding author: Jinhai Sun, sunjinhai@126.com
}

\begin{abstract}
With the development of the Internet, enterprise database has accumulated a huge amount of business data; the previous data mining technology is difficult to meet the current technical ability. In cloud computing environment, resources are stored in a distributed form, which is more efficient. In this paper, the authors analyze the sports industry financing mechanism by using data mining technology. Different from the developed countries, China's sports industry is still in its infancy, and sports industry investment and financing is the key to achieve the rapid development. Based on the analysis, we find that China sports industry investment and financing market degree is low, Capital market is difficult to achieve effective allocation of resources, and the improper allocation of resources tends to delay the development of sports industry. On this basis, we put forward relevant policy recommendations.
\end{abstract}

Keywords: Data mining, Sports industry, SVM algorithm, Financing mechanism

\section{Introduction}

With the development of economic globalization and the popularization of physical exercise in the world, sports industry is becoming in twenty-first Century the most promising sunrise industry. Occupation sports club in order to survive in the fierce market competition and development and increasing capital investment, the fitness club in order to gain more market share in the country to open a new store, the sports industry's lack of investment funds has become increasingly affect China's sports industry can develop healthily and rapidly[1-2]. The development of sports industry is far from enough to realize the expansion of production by the accumulation of its own capital. And the situation in developed countries is different, China's sports industry is still in its infancy, on how to promote the healthy development of the sports industry is still in the groping. The development practice of sports industry in foreign countries has been fully proved that the sports industry investment and financing is the key to achieve the rapid development of sports industry[3]. The investment and financing mechanism refers to the relationship between the various elements of the investment and financing activities in a certain economic body and the function of the regulation of the operation of investment and financing[4]. Under the condition of market economy, the factors of investment and financing activities and their mutual constraints determine the complexity of the reform of investment and financing mechanism. Investment and financing mechanism mainly includes three aspects: the main body of investment and financing, investment and financing channels and investment and financing environment.

In this paper, through the data mining method to analyze the sports market in China, in order to promote the development of data mining, processing and integration of business 
applications to solve the distributed mass data analysis, put forward the cloud computing environment data mining solutions, through cloud computing ability and cloud computing service model, the paper describes the solution mechanism of data mining services the. Cloud computing environment data mining is a kind of information resources service mode under the network environment. Through cloud computing infrastructure as a service (IaaS), platform as a service (PaaS) and software as a service (SaaS) of 3 kinds of service model, data storage, computing equipment, development platform and application software hardware and software resources available to users in the form of services, the formation of an on-demand access computing services[5]. Computing services in this mode, users use cloud computing environment data mining, the application in the cloud platforms is not concerned with all kinds of data mining, but according to the data mining tasks, to maximize the use of resources in data mining service cloud platform, including computing resources, storage resources, application resources. In cloud computing environment, data mining is a kind of network computing resources, and its essence is a kind of service model. The task of data mining to the user cloud is a cloud service; execute data mining operation processing and storage space are regarded as service resources, task related database, data warehouse, data mining algorithms can be regarded as special resources to support data mining services.

\section{Data Mining and Support Vector Machine}

\subsection{Data Mining under Computing Environment}

Cloud computing is the further development of distributed computing, parallel computing, grid computing and utility computing based on high speed bandwidth and virtualization technology[6]. At present, cloud computing is still in the primary stage of research and application, and has not yet formed a unified standard and definition. Analysis and synthesis of many cloud computing definition, we can conclude that their basic features: the cloud environment has the ability to store and large scale computing resources, and architecture with dynamic scalability, and through virtualization technology and a huge pool of resources to provide services[7]. These characteristics of cloud computing make it possible to store, analyze and apply the data, and make the data mining in the cloud computing environment become a research field with theoretical and applied value. With the expansion of business growth and business scope, the enterprise database has accumulated business data, the traditional data mining model cannot meet the massive data mining demand for computing power, therefore it is necessary to set up a new data mining capability of high performance computing mode.

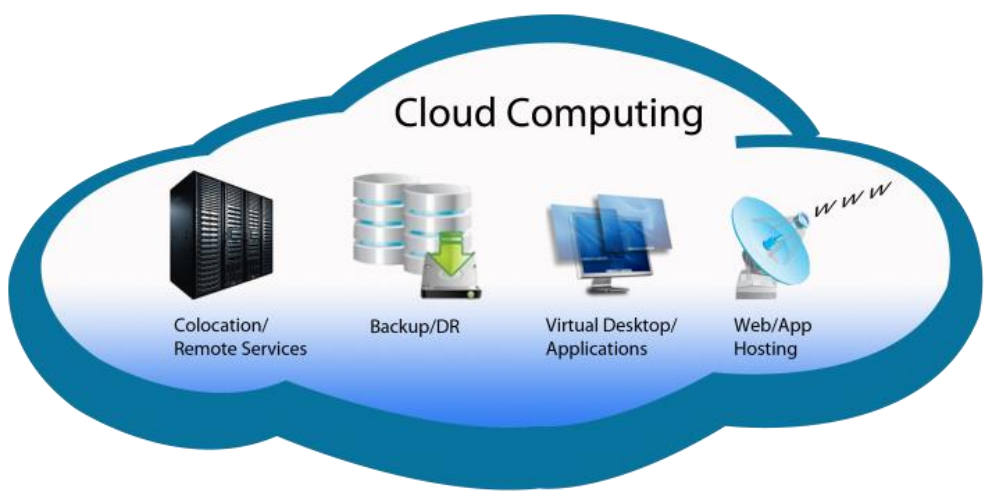

Figure 1. Cloud Computing 
Data mining is a collection of service function, behavior data mining techniques, including data selection, data preprocessing, data mining, integration, analysis, and evaluation results, by mixing and collocation of these functions, the formation of new composite applications. Cloud computing has built a network environment, which can realize the sharing of computer equipment, storage equipment, server cluster, integrated development environment, application software and so on[8-9]. On this basis, through virtualization, component, interface and integration technology, hardware and software package will be packaged into the corresponding service module, response infrastructure, platform development and application of 3 users on different levels of service requests, namely IaaS, PaaS and SaaS, in order to achieve a complete service mode. Based on this, the cloud computing environment of data mining can provide users with a set of data mining development and application of the necessary capabilities, to provide a good solution for data mining services.

Infrastructure services are based on data center services, in order to provide services to the form of data mining to calculate the resources needed, and provide remote access to these resources. The data resource service provides the service of the remote managed database, so that the user can use the remote data resources as well as the local database, and provide the requirement driven database and data warehouse technology. The process of data mining service business process services across multiple systems, data mining is the key module and the data binding information, form element application mining process, mining process to create remote resources[10]. Application services, also known as software as a service, the data mining applications as a whole, through the network platform to deliver to the end user. The test service tests the data mining system delivered by the local data mining system or the cloud platform through the remote hosted testing tools. The service platform provides remote service development and application of data mining, including application development, interface development, database development, storage, integration, deployment, testing and operation and maintenance function, users can create enterprise application in data mining.

\section{Cloud Services Architecture}

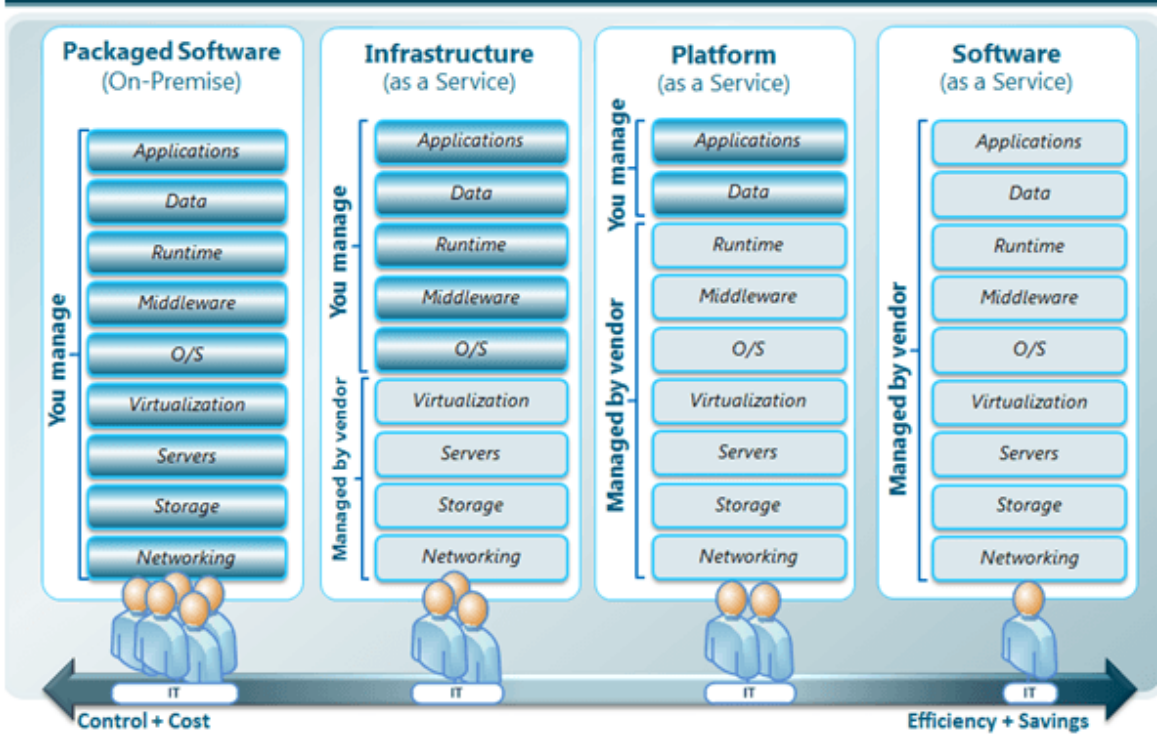

Figure 2. Cloud computing service architecture 


\subsection{Support Vector Machine}

Approximate linear separable support vector machines, also called soft interval support vector machines, are in the case of linear separable. Here we consider a loss function of SVM, the original problem is constructed as:

$$
\begin{array}{cc} 
& \min \frac{1}{2}\|w\|^{2}+C \sum_{i=1}^{l} \xi_{i} \\
\text { s.t. } \quad & y_{i}((w \cdot x)+b) \geq 1-\xi
\end{array}
$$

The Lagrange function of the original problem is introduced:

$$
L(w, b, a)=\frac{1}{2}\|w\|^{2}+C \sum_{i=1}^{l} \xi_{i}-\sum_{i=1}^{l} \alpha_{i}(((w \cdot x)+b)-1+\xi)
$$

The extreme conditions are available:

$$
\begin{aligned}
& \nabla_{b} L(w, b, a)=0 \\
& \nabla_{w} L(w, b, a)=0 \\
& \nabla_{\xi} L(w, b, a)=0
\end{aligned}
$$

The sample points on the two standard hyper planes are called support vectors, and the name of the support vector machine is obtained. Define the classification interval (margin) as:

$$
\rho=2 r=\frac{2}{\|w\|}
$$

As a result, the optimization problem for linearly separable SVM is:

$$
\min J(w, b)=\frac{1}{2}\|w\|^{2}
$$

The above problem is the main problem of SVM, which is a convex two optimization problem. The problem can be solved by constructing the Lagrange multiplier method to solve the problem.

$$
\begin{gathered}
\max W(\alpha)=\sum_{j=1}^{l} \alpha_{j}-\frac{1}{2} \sum_{i . j=1}^{l} \alpha_{i} \alpha_{j} y_{i} y_{j} x_{i} x_{j} \\
\sum_{j=1}^{l} \alpha_{i} y_{j}=0
\end{gathered}
$$




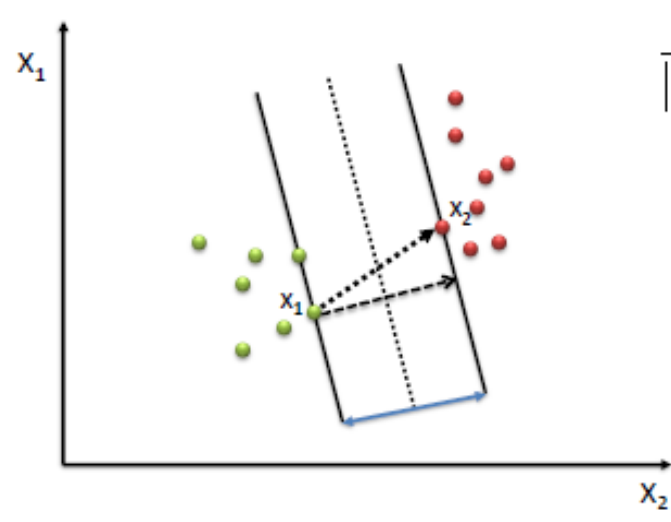

$\frac{w}{\|w\|} \cdot\left(x_{2}-x_{1}\right)=$ width $=\frac{2}{\|w\|}$

$w \cdot x_{2}+b=1$

$w \cdot x_{1}+b=-1$

$w \cdot x_{2}+b-w \cdot x_{1}-b=1-(-1)$

$w \cdot x_{2}-w \cdot x_{1}=2$

$\frac{w}{\|w\|}\left(x_{2}-x_{1}\right)=\frac{2}{\|w\|}$

Figure 3. SVM Classification

\section{The Investment and Financing Mechanism of Sports Industry based on Data Mining}

\subsection{Application of Data Mining in Sports Industry}

The two concepts of data mining and knowledge discovery in databases (KDD) are closely related, and are generally considered to be equivalent. Data mining is a multiinterdisciplinary fusion formation of disciplines, including database systems, statistics, machine learning, artificial intelligence, visualization, information science, integrated the mature methods and tools in many disciplines. Its main methods are statistics, association rule, decision tree, neural network, rough set, Web mining, etc.. Data mining is a new and effective information technology with strong vitality. It has been widely used in the field of sports, but it also has some problems in practical application. Compared with the application of data mining in other fields, the application of data mining in the field of sports started relatively late, but the results have been achieved for all to see. In order to make a lot of games in the field of sports tactical data, the national physique monitoring data movement data, give full play to the potential value of data mining in the research work in the field of sports and many urgent. Include the following aspects: one is to establish a data platform of sports, through this platform will be mining research in the field of sports data resources, provide data sharing platform for the sports science and technology workers; two is the general mining tools and popularization, common mining tools integration of a variety of mining methods developed on the basis of the study and, without too much knowledge related professional can operate user interface. Three is the cross integration with other technologies, such as the data mining technology and the sports system simulation of the project will have a wide range of subjects cross. 


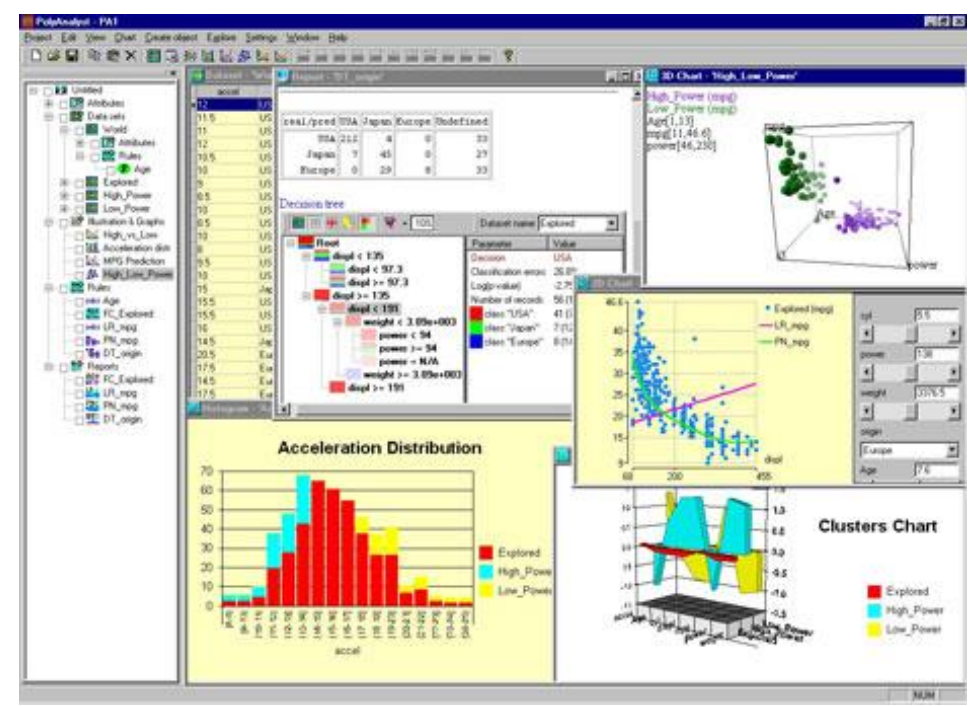

Figure 4. Data Mining

\subsection{Status of Investment and Financing in Professional Sports Market}

Professional sports clubs are the highest social concern and the most competitive part of the whole sports industry. The United States government budget management agencies will be defined as the occupation Sports Club: mainly engaged in sports provide on-site performance pay attention to the enterprise, to provide sports games to consumers in order to meet the needs and demands of consumers in terms of sports and entertainment. Most of the professional sports clubs in our country are invested by the strength of the enterprise, the club's daily expenses have a reliable guarantee. In the capitalist private economic system, the pursuit of return on investment is the basic guidelines for any investor to pursue. Professional sports club as an independent economic entity, the investment of the club is bound to consider its return on investment. The rapid development of professional sports in the United States is due to the high rate of return on investment in sports industry, thus attracting more high-quality capital into sports industry. With the expansion of the professional sports market, more and more funds begin to enter the professional sports market. In the daily management of the club, because of property rights, economic interests and other factors, the main problem of the investment and financing has more and more influence on the survival and development of the club.
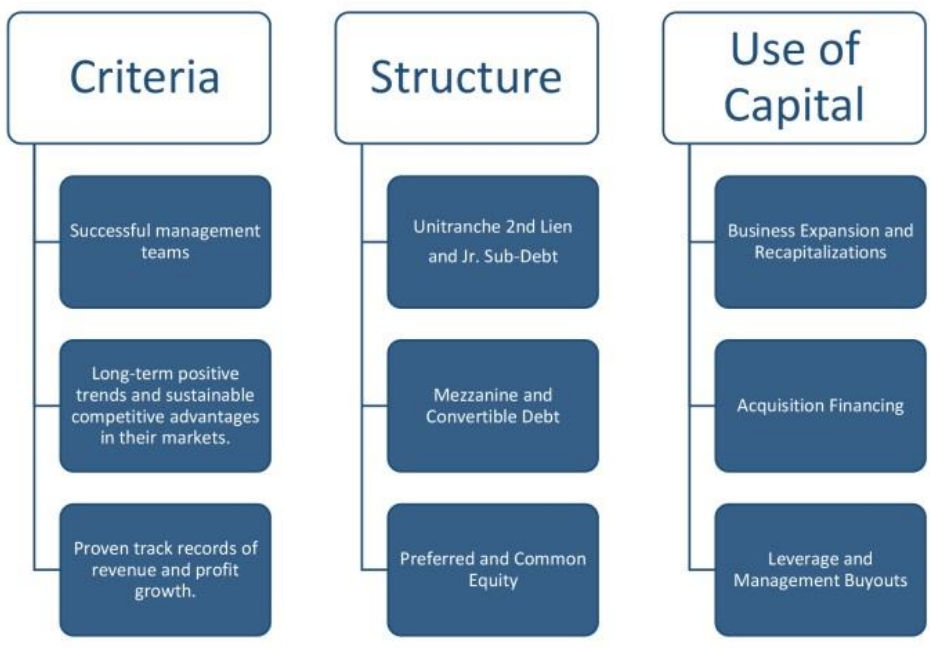

Figure 5. Investment and Financing Strategy 
- The nature of the investment subject is not clear: the difference of the main attributes of the investment and financing leads to the difference of the ability of the club market. From the perspective of the ownership structure of professional sports clubs in the sports industry developed countries, almost all of which are private capital investment. At present, the main body of the investment of professional sports clubs in China is the strength of state-owned enterprises and private enterprises, which accounted for the vast majority of state-owned enterprises. The state-owned enterprises are often only concerned about their own social influence, while ignoring the club's competitiveness and investment benefit, to establish an effective responsibility system and the corresponding supervision and evaluation mechanism, the development of the club and therefore lack of stability and long term. It can be said that it is difficult to avoid the risk of club management in the process of occupation sports club investment of state-owned enterprises, seriously affect the process of marketization of China's sports industry, but also hindered the social capital into the sports industry.

- The subject of investment and financing responsibilities unclear: financing right unclear problems mainly exist in the club and Sports Bureau joint pattern club. On the one hand, the Sports Bureau has the ownership of the club coaches and athletes, and the ownership of the training facilities. On the other hand, the club investors have certain restrictions on the use of funds for the club. In the daily operation of the club, both strive to get more right, take as little as possible inputs, often after problems both sides shirk responsibility, which affects the normal operation of the club.

- Financing channels of a single: low interest rates of professional sports clubs is the root cause of the difficulty of bank loan financing. Poor professional sports club profitability, investment funds cannot effectively recover the difficulties caused by refinancing. In recent years, commercial banks are invariably started strategic adjustment of credit scale, our country occupation sports clubs because of poor profitability, low credit rating, is often regarded as high risk customers and not in the strategy.

\subsection{Fitness Club Investment and Financing Situation}

Fitness club is to enhance the professional aerobics, equipment training, ball and so on as the main content, the development of sports fitness project as the main form, the sports fitness and related services as the venue for the exchange of goods. Fitness club's core product is to provide consumers with exercise, fitness and leisure venues, equipment, services and professional guidance, product form in order to intangible services. In the sports industry developed country, the fitness club is the largest and most effective sports enterprise. According to the theory of public goods, the service provided by the fitness club has the attributes of private goods. Our country fitness club enters the market operation time earlier, has formed a set of mature modern enterprise operation system. The number of fitness clubs in our country is huge, and the investment subjects are Chinese and foreign joint ventures, private enterprises, foreign investment and so on. Fitness club financing is mainly due to the owner's own funds, the lack of fitness clubs can be mortgaged to the bank assets, can not get enough bank loans. In addition to the investor's own funds, the fitness club usually use a prepaid consumer mechanism as a means of financing. The advance of the consumption mechanism of enterprises, have a large amount of credit card, the business income is very considerable, but for a brand, the long-term development of enterprises, in the operating profit source is more important. 
At present, the fitness club's profit model is single, the income is mainly the club membership fee, depending on the membership system for the business model of the sustainability of the existence of certain questions. The endogenous financing of the fitness club is mainly used in advance payment mechanism. Fitness industry is now widely used in advance consumer mechanisms for both consumers and businesses are faced with the risk. Prepaid fitness card is like a bank credit card, the operator can get funds in advance, but if you do not find a variety of profit points in the middle and late, it is difficult to maintain. Because prepaid consumption can be regarded as a kind of financing behavior, businesses have complete control over the advance, they can take a one-time investment, consumers can not return the card at any time, take their money. The sports consumption of city residents is mainly composed of Chinese watch sports, sports magazines, books and buy the purchase of sports apparel and sports fitness consumption, including the purchase of sports fitness equipment form.

Table 1. Monthly Sports Consumption Structure of Urban Residents

\begin{tabular}{|l|l|l|l|l|l|}
\hline type & $\begin{array}{l}\text { Watch } \\
\text { sports } \\
\text { games }\end{array}$ & $\begin{array}{l}\text { Buy books } \\
\text { and } \\
\text { magazines }\end{array}$ & $\begin{array}{l}\text { Sports } \\
\text { apparel }\end{array}$ & $\begin{array}{l}\text { Athletic } \\
\text { sports }\end{array}$ & $\begin{array}{l}\text { Sports } \\
\text { Lottery }\end{array}$ \\
\hline Amount & 365 & 213 & 502 & 129 & 31 \\
\hline Proportion & $29 \%$ & $16 \%$ & $45 \%$ & $9 \%$ & $1 \%$ \\
\hline
\end{tabular}

\subsection{Investment and Financing Situation of Sports Stadiums}

At present our country stadium management, full budget management venues is less and less, the difference between the budget management of the venues accounted for most of proportion, in addition, with more and more venues contract and leasing management mode, more conducive to mobilize their enthusiasm, improve operating efficiency, realizing the transformation from administrative management to management. Stadiums in China invested by the government as the main _, private capital in a few. The initial investment of China's large stadiums construction is basically by the central and local government investment, the construction of stadiums and sports development and promote national health by the government as a responsibility and obligation, namely stadiums investment in China is the main country and all levels of government. Due to the construction of the stadium needs huge financial support, the construction of the stadium and the capital is difficult to recover in a short time, which also resulted in the capital of China's most of the stadium can only be built by the state to invest. Large sports venues in China to invest in the construction of the program is generally by the government sports administrative department or the National Olympic Committee of city planning and construction of large game in accordance with the venue plan, put forward relevant ideas and construction of venues construction, by all levels of government is responsible for construction. The central government is responsible for the construction of key sports venues, such as the construction of the Olympic Park, local public sports venues in the construction of local government investment, the central government as the case, as appropriate. Because our stadium financing is mainly the government, so the vast majority of China's stadiums financing channels mainly by government funds, after the completion of the stadium capital mainly rely on financial subsidies and their business income venues. 


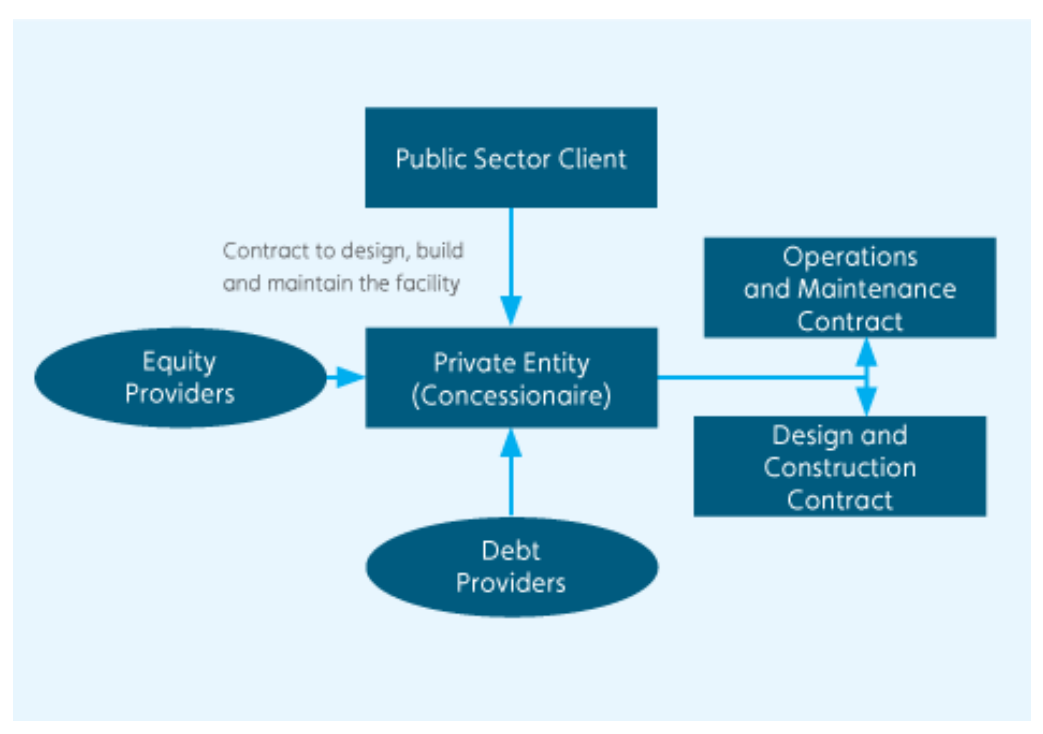

Figure 6. The PPP Mode of Financing

Investment and financing environment has the following three characteristics:

1) Systematic: The system is refers to the investment and financing environment is the organism which is integrated by many factors, is a complete system. Each factor in the system affects the change of investment and financing environment. This requires the main investment and financing in the process of analysis, evaluation of the investment and financing environment to fully consider all factors, the most reasonable way to choose. The sports industry as an emerging industry with the traditional third, the first and the second industries more dependent on the political and economic environment, cultural environment, the natural environment requirements are relatively low, which requires the investment and financing environment in the evaluation should be focused on.

2) Dynamic property: In the process of economic operation, some factors of investment and financing environment will change over time, so that the investment and financing environment itself is changing. On the one hand, these factors change the investment and financing environment in two positive and negative impact on the investment and financing activities, such as improving the positive effect of the improvement of infrastructure, the legal system of the negative consequences or the destruction of the ecological environment. On the other hand, the investment and financing of the main investment and financing environment of the evaluation criteria is also changing. In the different stages of the development of investment and financing, the investment and financing environment has different emphasis. The dynamic nature of the investment and financing environment makes us realize that the investment and financing mechanism of sports industry will continue to evolve with the improvement of China's overall investment and financing environment.

3) Difference: The influence and restriction of investment and financing environment on investment and financing activities are different. There are differences between different regions in the investment and financing environment, and the existence of regional economy is the basis of the existence of this difference. Different economic regions of natural history, political environment, economic development level, human resources and other factors are the basis and 
premise of the difference of investment and financing environment. The specific characteristics of the investment and financing environment, can make the investment and financing subject according to their own advantages to choose investment direction and financing channels. The regional difference of economic development of our country is big, there are big difference between the East and the West in the economy, social culture and so on, which requires the complexity of the sports industry investment and financing activities.

\section{Reform of Investment and Financing Mechanism of Sports Industry}

The reform of investment and financing mechanisms Chinese sports industry refers to the target through the reform of sports industry investment and financing mechanism should be able to maximize the development of the sports industry to address the constraints of Chinese original mechanism in disorder, and the new mechanism to achieve optimal efficiency, so as to promote China's sports industry healthy and orderly development. In the face of the low efficiency of China sports industry investment and financing mechanism, the plight of the contradiction between the supply and demand of investment and financing, how to solve this contradiction has become the motivation of the current Chinese sports industry investment and financing mechanism reform. The financing mechanism of the reform of the sports industry China landing point is the service Chinese sports industry, sports industry investment and financing mechanism reform aims to overcome all the unfavorable factors hindering the development of the sports industry China, realize the development of the sports industry Chinese.

- The rationalization of the proportion of investment and financing: At present, the main source of China's sports industry investment capital for bank lending and industry capital, China's sports enterprises to enter the capital market direct financing difficulties, the number of sports industrial investment fund small scale, resulting in China's sports enterprises to raise funds in the capital market is still very small. This financing structure on the one hand reflects the financing difficulties of China's sports industry, on the other hand, it reflects the size of the development of China's sports industry is small. Due to the small scale of bank lending and the slow accumulation of industry capital, the rapid development of sports industry in our country has hindered the development of sports industry in China. And through the capital market, the issue of corporate bonds, sports industry investment fund and other ways to help our sports enterprises to obtain sufficient capital to improve the management of sports business.

- Marketization of investment and financing allocation: In countries with developed market economy sports industry comparison, Chinese sports industry marketoriented financing investment is low, the capital market is difficult to achieve the reform of sports industry resources allocation, the allocation of resources caused by improper damage tends to slow pace of development of the sports industry China. Under the condition of incomplete market, the existence of the differential treatment between the private enterprise and the state-owned enterprise makes the problem of the shortage of funds of sports industry in our country. Sports industry to achieve the allocation of investment and financing market is conducive to the overall strength of China's sports industry to upgrade.

- The promotion of international competitiveness: International industry competition has become an indisputable fact, in a competitive disadvantage industry tends to cause the domestic industry to shrink, and even the same industry in his country as a substitute, directly endanger the country's industrial safety. The present low international competitiveness China sports industry is an indisputable fact, NBA, the Premier League, the Champions League and other foreign events attracted the 
majority of our sports consumers, foreign sports club to earn a lot of money from China, the overseas outstanding sports operation company operation in China the most good occupation league. In foreign sports enterprises quickly into the real threat Chinese front, China national sports industry has been seriously challenged, to enhance the international competitiveness of China sports industry has become an urgent requirement for maintaining the security of national culture, show the national status.

A good investment and financing mechanism can reduce financing costs, improve financing efficiency, improve the efficiency of cooperation between various economic entities, and ultimately enhance the investment strength, strengthen investment decisionmaking status, inappropriate investment operation mechanism, financing and use will hinder investment funds, funds will decrease the efficiency of deterioration the economic relationship between the various economic entities, eventually forcing investors to reform. Giving full play to the basic role of the market in the allocation of resources is the basic requirement of the socialist market economy in China, and the main position of the investment and financing of enterprises is the theme of China's investment and financing reform. In reality, the main body of investment is divided into government, enterprise and residents. Due to the different identity of investors, their investment objectives are also different. Private investors are focusing on the investment return of the size, the most concern is whether the investment income maximization; institutional investors in addition to pay attention to maximize the return on investment, but also pay attention to the development of enterprises and expand market share; the government investment is mainly for the community to provide public goods, make up for the defects of the market and the macroeconomic adjustment. Accelerate the reform of sports enterprises, so that enterprises become the main body of investment and financing. According to the present situation of occupation of the sports club, the company in accordance with the modern enterprise system reform "skewness requirements clear property rights and responsibilities clear, separating, responsibility and risk control mechanism of clear subject of investment and financing, the occupation sports club can bear civil responsibility and obligation of independent, unified real Club investors rights and obligations, improve business actively investors.

\section{Conclusions}

The research on the investment and financing of sports industry in China is an important part of the sports industry in our country. At present, the main problems of China's sports industry investment and financing is the operation of sports industry investment and financing mechanism is not smooth, the market economy is difficult to effectively play a basic role in the allocation of sports industry resources. Compared with the state-owned investment, private investment profit is stronger, the higher efficiency of capital will become an important driving force China economic growth, at the same time in solving the employment, development of middle class has obvious superiority. China future investment growth will mainly rely on private investment, the development of the private economy can more effectively promote the capital and labor free flow and optimized allocation of production factors, which is the sustainable development of Chinese endogenous dynamic economy and largest source. The establishment of a financing mechanism for private capital into the sports industry mainly includes the following aspects: perfecting the preferential tax policies for private capital to participate in the sports industry, the difference of income tax cuts, reduce the burden of private sports enterprise management, improve the share of private sports enterprises profits; standardize the market competition behavior, protection of private sports enterprises with the state-owned enterprise sports fair market environment; to encourage private enterprises to increase investment in research and development of sports, to give financial 
support of private sports enterprise innovation, improve the market competitiveness of private sports enterprises.

\section{Acknowledgments}

The work of this paper is supported by the research of shandong sports industry transformation and upgrading.

\section{References}

[1] S.Park, H.Keh, "Modeling hybrid distribution channels: a game-theoretic analysis",Journal of Retailing and Consumer Services, Vol.10, (2003), pp.155-167.

[2] K.Cattani, W.Gilland, "pricing strategies for amanufacturer adding a direct channel that competes with the traditional channel", Productionand Operations Management, Vol.15, (2006), pp.40-56.

[3] Z.Huang and M.Benyoucef, "From e-commerce to social commerce: A close look at design features",Electronic Commerce Research and Applications, Vol.12, No.4, (2013), pp.246-259.

[4] D.Jutla and P.Bodorik, "Developing internet e-commerce benchmarks",Information Systems, Vol. 24, No. 6, (1999), pp. 475-493.

[5] D.Yao, Q.Liu, "Competitive pricing of mixed retail and e-tail distribution channels", Omega, Vol.33, (2005), pp.235-247.

[6] A.Enders, T.Jelassi, "The converging business models of Internet and bricks-and retailers",European Management Journal, Vol.18,(2000),pp.542-550.

[7] K.Anand, "Context-general and Context-specific Determinants of Online Satisfaction and Loyalty for Commerce and Content Sites”,Journal of Interactive Marketing, Vol. 24, No. 3, (2010), pp. 222-238.

[8] A.Niklas and S.Fredrik, "Electronic commerce, marketing channels and logistics platform-a wholesaler perspective” ,European Journal of Operational Research, Vol. 144, No. 2, (2003), pp. 270-279.

[9] C.Druehl, E. Porteus, "Price competition between an Internet firm and a bricks and mortar firm", Working Paper, (2001),pp.24-30.

[10] J.Kim, "The role of etail quality, e-satisfaction and e-trust in online loyalty development process",Journal of Retailing and Consumer Services, Vol. 16, No. 4,(2009), pp. 239-247.

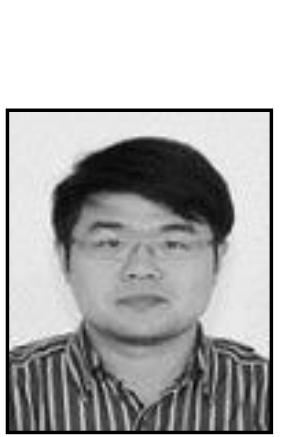

\section{Authors}

Wang Hao. He received his master degree in Political Economy from Shandong University. Now he is a in reading doctor of Qufu Normal University, majoring in Sports Humanidtic Sociology and his research orientation is sports industry. He is now working in Shandong Sport University. 